\title{
Historein
}

Vol $13(2013)$

Questions and Orientations in History during the last 20 years. Part 2

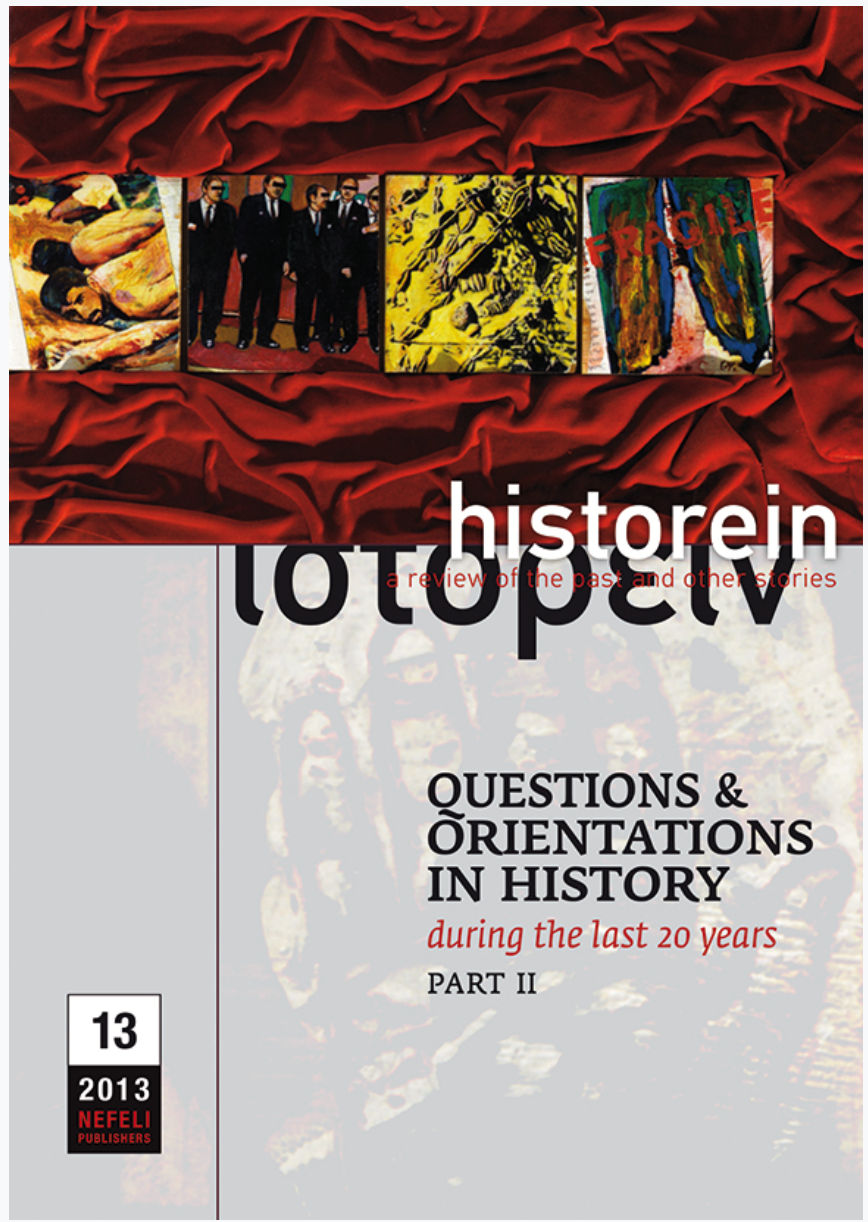

Review of Antonis Liakos's Aпoкá $\lambda u \psi \eta$, Outoría

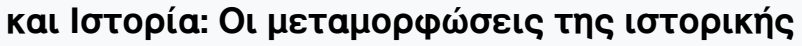

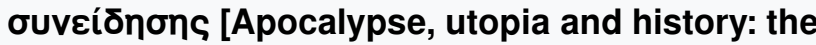
transformations of historical consciousness]

Yannis Stavrakakis

doi: $10.12681 /$ historein.238

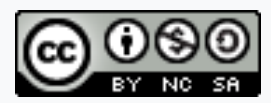

This work is licensed under a Creative Commons Attribution-NonCommercialShareAlike 4.0.

To cite this article:

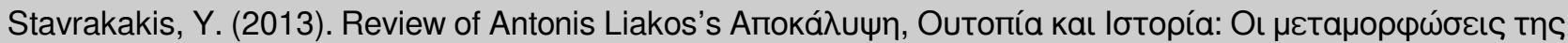

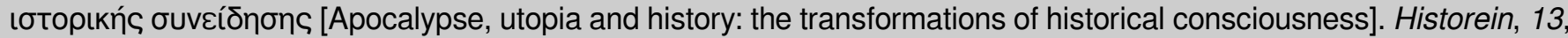
104-107. https://doi.org/10.12681/historein.238 
cepts of cultural policies - the proclamation of a "savant" art, which deserves to be protected by the state and is not subject to the laws of the market - in favour of a culture of divertissement, which is not entitled to such protection due to its massive appeal; fourth, an increasing justification of the necessity of cultural policy based on its contribution to economic development and in striking a balance between the social diversity of nations.

In an era of tremendous social and political change, and where the comparative approach has arrived at the heart of scientific research, the present edition is an "exercise of active memory". It enables the exchange of valuable knowledge and experience at a high level of expertise in the field of cultural policy. It is certain that it will serve as a powerful instrument in the hands of everyone who seeks to determine what it really means to have a public policy at the service of culture and how this policy could be improved if seen in the light of international theory and practice.

\section{Antonis Liakos}

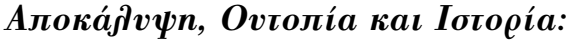

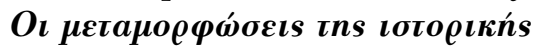 ovveíbnons}

\section{[Apocalypse, utopia and history: the transformations of historical consciousness]}

\section{Athens: Polis, 2011.478 pp.}

\section{By Yannis Stavrakakis \\ Aristotle University of Thessaloniki}

According to many accounts, we are currently going through a crisis of groundbreaking, even epoch-changing, proportions. The future of capitalism and democracy hangs in the balance, with the link between them - galvanised, in the west, by the welfare-state compromise - weakening continuously, opening the road to all sorts of unpredictable outcomes within an extremely volatile global picture. How can we imagine the future? Is there anything that guarantees the realisation of the desire invested in the products of our imagination? And how does our perception of the past influence this process? All these questions, brought once more to the fore by the global crisis, are hardly new; they have existed alongside the development of historical consciousness since antiquity. Examining how different societies and social groups, different eras and intellectual traditions (religious, political, scientific, etc) have dealt with such issues can prove an invaluable resource in assisting us in our present predicament. This is the daunting task that Antonis Liakos sets himself in this new book. And it is a task that he manages to bring to fruition with incredible erudition and attention to detail, by articulating a vast number of sources and accounts in a coherent, 480-pagelong argument, which is both instructive and 
pedagogical in its scope as well as powerful and challenging in its implications.

From the outset, Liakos makes clear what the reader is to expect from his inquiry: "How can [people] think, if possible in a comprehensive way, the past, the present and the future? How can they reflect on all the utopias that have vanished, utopias that transformed into dystopias as well as realities that proved to be postutopian? The subject of the book is this question: How - through the expectations, the fulfilments and the frustrations - was our historical consciousness transformed?" (16). It becomes clear that the aim of the book is to study the transformations marking our relationship with the past, both in terms of the discursive repertoires employed to conquer, represent and control access to it (religious texts, utopian narratives, scientific historical traditions, etc) and in terms of the (individual and collective) desires guiding these articulations and over-determining their future-oriented axis. In other words, "historical consciousness is to be examined in relation to apocalypse, utopia and history" (18). Past and future, fear and hope, destruction and construction are thus to be studied in their - often overlooked mutual engagement. This is obviously a long and demanding journey; in order to facilitate our participation in it, Liakos has organised his material into three distinct parts:

The first part deals with the formation of historical consciousness from the early Christian years to the beginning of modernity, when apocalypse, utopia and history antagonised each other in constructing the new world. In the second part we will see history autonomising and transforming itself, through the Enlightenment and the scientific revolution, through the scientific and technological will to change the world. Finally, in the third part, which is concerned with the twentieth century and its implications, we will engage with the paradox of turning to history through the boldest experimentations with the future. We will encounter the entanglement with history at the same time that its meaning was lost. The creation of a historical culture. (18-19)

By imaginatively staging the dialectical encounter between these three moments or tropes - apocalypse, utopia and history - Liakos reveals the latent currents linking them together. Utopia and history are thus revealed as two distinct but interconnected types of discursive architectonics, of the past and of the future, that cannot exist in separation. What is at stake here, then, is to explore the mutual engagement between historical and utopian thought. As for the linkage between utopia and apocalypse, here the connection is more obvious to the extent that utopian discourse has often reoccupied a millenarian terrain of temporality, genealogically linked with earlier apocalyptic and eschatological narratives. In turn, history has structured historical time in ways that can only be illuminated through a comparison between the philosophy of history and eschatological grammar.

It is obviously very difficult to do justice to such a complex, dense and extensive argument within the scope of a rather limited review. I will try, however, to highlight some of its extremely productive aspects and stress some of its innovative conclusions. For a start, it is important to register the critical distance that Liakos takes from an idealised understanding of his own profession: he is very much aware of the different types of historein, the different ways in which distinct cultures represent their past; in addition, he is not afraid to accept the constitutive ambiguity that this recognition introduces into his subject-matter (61). But, interestingly enough, this distance does not 
translate into cold detachment; on the contrary, the way he presents the relation between history and prophecy, the apocalyptic imaginary, and the implications of eschatological temporality all reveal empathy and a strong determination to trace the importance of such phenomena for our current predicament. In addition, the accounts offered manage to capture the antithetical political investments and uses in which theological concepts have been implicated, sanctioning both historical continuity and obedience as well as rupture and revolutionary change $(112,132,139)$.

This constitutive ambiguity that Liakos is so good at acknowledging must have been, however, intolerable for many (individuals and communities) throughout the ages. In fact, modernity itself has marked an attempt to escape this ambiguity and refound human consciousness and behaviour on new rational, objective and stable grounds (148). By embracing modernity and the nation-state, by becoming in its turn a mechanism that uses the past to consecrate and legitimise the present, historiography detached itself from envisaging an alternative future, something that became the constituency of utopia (165). Here Liakos' ability to map the complex dialectic between utopia, history and power relations, between what is recognised as scientific/progressive and what is not, and - most importantly - between the "benign" and the "malignant" repercussions of what counts as science (the case of theories of evolution is indicative in this respect, see 222) is to be thoroughly recognised and celebrated. The same applies to his treatment of the relationship between historical consciousness and national identification, something he has already researched in his previous work.

What marks the radical crisis of the utopian imaginary - with all its eschatological overtones - is clearly the dystopian realities pro- duced by the attempts to implement it within modernity (with the Holocaust and the Gulag being two associations that immediately spring to mind). Liakos follows closely this crisis and traces the new (ethicopolitical) burdens and challenges it places on historical discourse: history assumes the role of a redemptive process of recognition of past traumas, the public function of collective memory (319). However, this role and this function can only be something articulated a posteriori through the active intervention of the historian as a bearer of a particular ethical duty or collective mission. At the same time, it marks the evacuation of history itself from meaning, an aporia registered in contemporary historiography. Liakos relates this development with antihumanist trends in European philosophy and gradually articulates its more promising aspects as they have been reflected in English social history, where the intellectual praxis of history involves an (ethicoscientific) exercise enabling us to escape determinism and acknowledge the openness of the future (346-7). The postmodern turn, the debate on the so-called "end of history" and the limits of the human in an age of cyborgs constitute the topical themes bringing this long journey to a close. This indeed remains an open-ended exercise and the reader is left in an aporetic state. However, Liakos' accomplishment is that this is not a frustrated aporia, an aporia that induces ontological uncertainty and angst; precisely because by going through the 480 pages of the book, on top of accumulating useful information, the reader has also acquired a new reflexive ethos, a new ability to deal with history and the multitude of challenges it poses.

Most importantly in my view is that this book will be able to cultivate this ethos in an audience that extends well beyond the group of professional historians. It is addressed to the average interested/learned reader and will 
prove a work of reference for years to come, both in terms of its rich content as well as of its straightforward and reflexive style. By avoiding any type of determinist argument, by opening itself to a type of informed, interdisciplinary free association, so much lacking from our academic literature, Liakos negotiates a safe passage through an immense variety of traditions and debates, endowing the reader with equal freedom to associate and draw her/his own informed conclusions. The result of meticulous study and of an unrelenting desire to highlight the intertextuality of historical discourse as a sign of richness and intellectual advancement, rather than as a danger for some sort of essentialist purity, this is a contribution of immense power and reach.
Nikolas Rose

The Politics of Life Itself:

Biomedicine, Power, and Subjectivity in the Twenty-First Century

Princeton \& Oxford: Princeton UP, 2007. 350 pp.

\section{By Vasia Lekka}

University of Athens

There is, it might be said, too much description, too little analysis, too little criticism. Where so many judge, however, I tried to avoid judgment, merely to sketch out a preliminary cartography of an emergent form of life and the possible futures it embodies. And in doing so, not to judge, but I hope, to help make judgment possible. To open the possibility that, in part through thought itself, we might be able to intervene in that present, and so to shape something of the future we might inhabit (258-259).

With these words, Nikolas Rose sums up quite successfully the main purpose of his The Politics of Life Itself: Biomedicine, Power, and Subjectivity in the Twenty-First Century. Rose, the author of major works in the field of social sciences, such as The Psychological Complex: Psychology, Politics and Society in England, 1869-1939 (1985), Governing the Soul: The Shaping of the Private Self (1989) and Powers of Freedom: Reframing Political Thought (1999), has done extensive work on a variety of issues, extending from eugenics to the constitution of the modern subject and the links between biomedicine, biopolitics and bioethics.

In recent decades, there has been a remarkable trend among historians, social scientists and philosophers to focus on the relations be- 